\title{
Soft tissue angiosarcoma of the breast in a patient with Klippel-Trenaunay-Weber syndrome
}

\author{
Angiosarcoma de tejido blando de la mama en un paciente con síndrome de \\ Klippel-Trenaunay-Weber
}

\begin{abstract}
Emmanuel Bugarin-Estrada ${ }^{1}$, Eliezer Villanueva-Castro ${ }^{2}$ and Heriberto Medina-Franco ${ }^{3 *}$
${ }^{1}$ Escuela de Medicina y Ciencias de la Salud del Tecnológico de Monterrey, Monterrey, Nuevo León, Mexico; ' Universidad Autónoma de Sinaloa, Culiacán, Sinaloa; ${ }^{3}$ Department of Surgery Division of Surgical Oncology, Instituto Nacional de Ciencias Médicas y Nutrición Salvador Zubirán, Mexico City, Mexico
\end{abstract}

\begin{abstract}
Angiosarcomas are neoplasms of blood or lymphatic vessels with aggressive behavior. We report the coexistence of this malignancy within soft tissue of the breast in a 49-year-old woman who was diagnosed with Klippel-Trenaunay-Weber syndrome (KTW-S) during childhood. The patient has no previous history of radiation therapy on the chest and does not have any known risk factor for developing angiosarcoma, except for her congenital disease. To the best of our knowledge, the association between soft tissue angiosarcoma of the breast and KTW-S has never been previously reported.
\end{abstract}

Key words: Angiosarcoma. Breast. Cancer. Congenic disease. Klippel-Trenaunay-Weber syndrome.

\section{Resumen}

Los angiosarcomas son neoplasias de los vasos sanguíneos y linfáticos con comportamiento agresivo. Reportamos la coexistencia de esta malignidad dentro del tejido blando de la mama en una mujer de 49 años que fue diagnosticada de síndrome de Klippel-Trenaunay-Weber desde la infancia. La paciente no tiene antecedentes de radioterapia en el tórax ni factores de riesgo conocidos para desarrollar angiosarcoma, a excepción de su enfermedad congénita. A nuestro saber, la asociación entre el angiosarcoma del tejido blando de la mama y el síndrome de Klippel-Trenaunay-Weber no había sido reportada previamente.

Palabras clave: Angiosarcoma. Cáncer. Enfermedad congénita. Mama. Síndrome de Klippel-Trenaunay-Weber.

\section{Introduction}

Angiosarcomas are soft tissue neoplasms that originate from endothelial cells. Most of these malignancies appear de novo; however, their presence has been described in patients with Klippel-Trenaunay-Weber syndrome (KTW-S) $)^{1,2}$. This syndrome is a very rare congenital condition in which patients have three major manifestations: cutaneous hemangiomas, venous varicosities, and hypertrophy of the limbs. It is known that a mutation in VG5Q protein plays a role in the pathogenesis of KTW-S due to its effect on angiogenesis ${ }^{3}$; nevertheless, this alteration has not been related to vascular malignant transformation. We

\section{Correspondence:}

*Heriberto Medina-Franco,

Vasco de Quiroga, 15 
found no evidence in the literature of the presence of an angiosarcoma in the breast in patients with KTW-S. However, it has been suggested that the appearance of angiosarcomas in this congenital disease may be related to impaired immunity due to arteriovenous fistulas that lead to chronic lymphedema or abnormalities in angiogenic factors ${ }^{4}$.

\section{Case report}

A 49-year-old woman, diagnosed with KTW-S at the age of 12 , presented with an asymptomatic, well-defined nodule in the inferior quadrants of her left breast. Imagining studies showed no calcifications on mammography. Breast ultrasound reported a solitary hypoechoic lesion with central and peripheral vascularity and no abnormal axillary lymph nodes. It was reported as BIRADS 4-B (Fig. 1).

She had a history of systemic hypertension, hypothyroidism, peripheral venous insufficiency, obesity Grade 2, chronic lower back pain, and previous history of smoking (0.5 pack years). No previous blood transfusions or radiations to the chest were reported.

10 days after the imaging studies were performed, the patient was followed up by her primary physician and a solitary nodule was detected on physical examination in the lower-inner quadrant of her left breast. It measured approximately $1 \mathrm{~cm}$ of diameter, it was fixed to deep structures, with no pain nor other changes on skin rather than a violaceous macule due to the KTW-S, and no axillary lymph nodes were detected. Other relevant findings on examination included hypertrophy of the left limbs, varicose veins on both legs, and port-wine stain with predominance on the left hemicorpus (Fig. 2). Diameter of the right arm, right forearm, left arm, and left forearm was $27 \mathrm{~cm}, 20 \mathrm{~cm}, 36 \mathrm{~cm}$, and $30 \mathrm{~cm}$, respectively. Diameter of the right and left legs was $40 \mathrm{~cm}$ and $50 \mathrm{~cm}$, respectively. Some varicose veins formed nodules on the right leg and a few of them were painful. CEAP classification of chronic venous disorders for this patient was the following: clinical-4 (skin changes without ulceration), Etiology-C (congenital), Anatomy-S (superficial veins), and Pathophysiology-R (reflux). Vessels were less prominent on the upper limbs compared to those found on lower limbs.

The lesion on her breast was excised 2 weeks later and it was identified as a low-grade angiosarcoma CD31 +, CD $34+$, factor VIII +, and CD240 - on the final histopathology report (Fig. 3). Excising of additional margins was required and reresection with wide

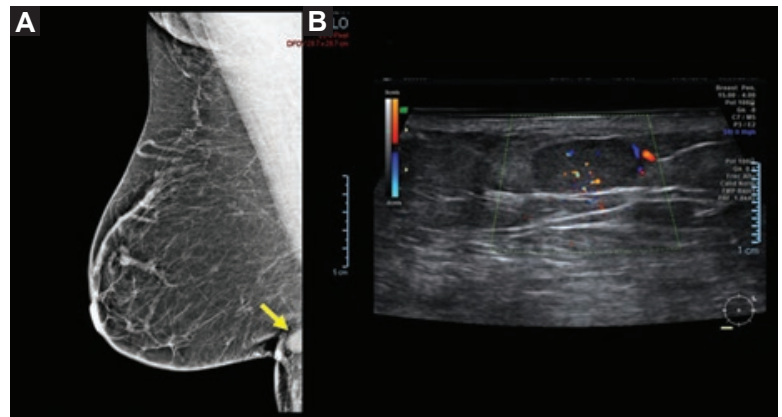

Figure 1. Imaging studies. (1A) Mammography showing a well-circumscribed, hyperdense lesion in the inner-lower quadrant of the left breast; BIRADS 4B (left mediolateral oblique view). (1B) Doppler ultrasound showing an oval, hypoechoic nodule, with well-defined margins, presenting central and peripheral vasculature.

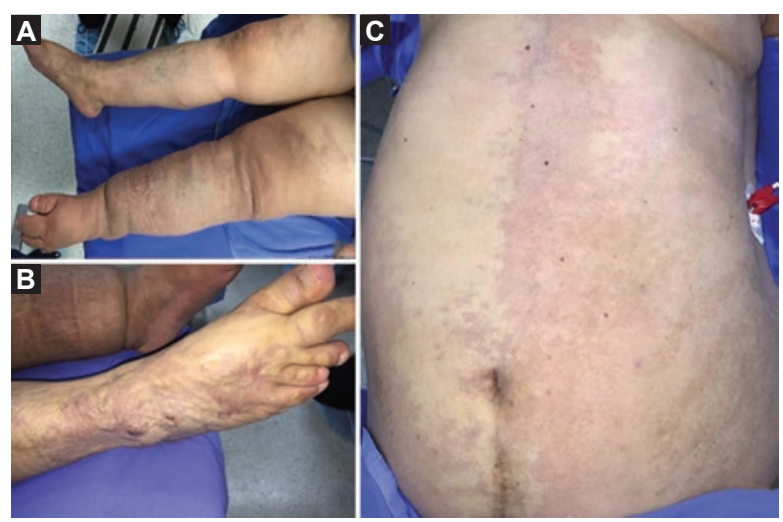

Figure 2. Patient with Klippel-Trenaunay-Weber syndrome. This patient had asymmetrical hypertrophy of the lower limbs (2A), with varicose veins $(\mathbf{2 B})$, and wine-port stain predominantly on the left hemicorpus with borders respecting the midline (2C).

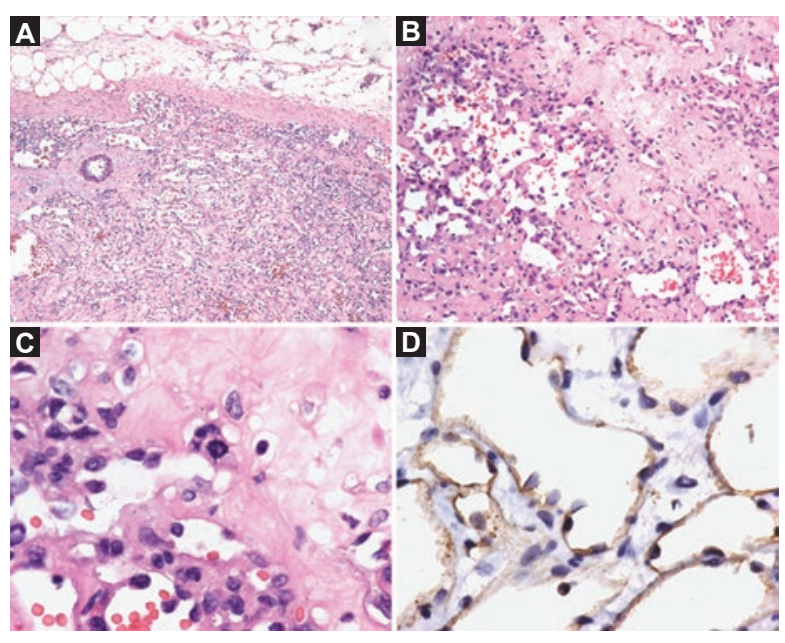

Figure 3. Low-grade soft tissue angiosarcoma of the breast. (3A) Area of vascular proliferation limited by a fibrous capsule adjacent to breast adipose tissue (Hematoxylin-Eosin, x4). (3B) Anastomosing vascular channels lined by abnormal endothelial cells (Hematoxylin-Eosin, $\times 10)$. (3C) Nests of large, mildly pleomorphic endothelial cells; some prominent nucleoli and mitotic figures can be seen (HematoxylinEosin, x40). (3D) Positive CD31 immunostaining of the tumor (x40). 
margins was performed 2 weeks later. The patient was scheduled for adjuvant radiation therapy.

\section{Discussion}

Angiosarcomas are non-epithelial malignancies characterized by proliferating cells derived from blood or lymphatic vessels. These are rapidly growing neoplasms that tend to recur locally 5 . During early stages, angiosarcomas are usually asymptomatic until they reach large dimensions. Several factors have been involved in the appearance of breast angiosarcomas such as radiation exposure following breast cancer or chronic lymphedema secondary to mastectomy or axillary lymph node dissection (Stewart-Treves syndro$\mathrm{me})^{6}$. Inherited conditions including neurofibromatosis Type 1 or Li-Fraumeni syndrome and exposure to environmental compounds such as arsenic and vinyl chloride have also been related; however, most of these neoplasms develop de novo in the breast? Some conditions known to predispose angiosarcoma development in other sites are KTW-S and Maffucci syndromes ${ }^{8}$; nevertheless, no cases have been reported in the literature showing association between the former syndrome and angiosarcomas in the breast.

KTW-S is characterized by congenital vascular malformations with a normal number of endothelial cells, contrary to blood vessel tumors in which the number of endothelial cells is increased. Although most cases are sporadic, there are some reports of an autosomal dominant pattern of inheritance. Mutations in the angiogenic protein VG5Q have been described in patients with KTW-S and its overstimulation promotes a higher formation of new blood vessels. This protein is encoded by the AGGF1 gene, which is highly expressed in the vasculature $^{3}$. VG5Q is secreted as new vessels are being formed, acting in an autocrine way on endothelial cells to induce their proliferation ${ }^{9}$. VG5Q mutation, known as E133K, is found in $<4 \%$ of patients with KTW-S ${ }^{10}$.

Clinical manifestations of KTW-S include the triad of cutaneous capillary hemangioma, varicose veins, and bony and soft tissue hypertrophy involving an extremity ${ }^{11}$. The hemangioma is usually the first sign to appear and it tends to be unilateral, with borders respecting the midline of the body. Its depth is variable and it may be limited to the skin or affect deeper structures. Capillary malformations have also been reported in the pleura, liver, spleen, colon, and bladder. Bleeding from visceral organs is a major complication that may manifest as hematuria or hematochezia $^{12}$. The existence of arteriovenous fistulas is another important feature of this syndrome and can be detected by the presence of a pulsatile mass or thrill on physical examination. Limb hypertrophy can be secondary to bone or soft tissue involvement; it is usually present at birth and progresses as the patient ages $^{13}$.

In 2010, Simas et al. described a patient with KTW-S in a 22-year-old man with a diffuse angiosarcoma in one of his leg secondary to chronic lymphedema linked to Stewart-Treves syndrome ${ }^{1}$. It is known that arteriovenous fistulas in patients with KTW-S are associated with venous hypertension and may lead to chronic lymphedema. The affected tissue can be predisposed to vascular malignancies due to continual angiogenic stimulus and immune disturbance caused by impaired trafficking of dendritic cells and lymphocytes ${ }^{4}$.

Another case has been reported in a 46-year-old patient with KTW-S who developed an angiosarcoma adjacent to a malignant peripheral nerve neoplasm in his right leg2. The patient went through an amputation of his limb and died later due to pulmonary and cerebral metastases.

In the case, we are presenting, no significant risk factors for the development of angiosarcoma were found such as previous radiation exposure or axillary lymph node dissection. It is not clear if the presence of arteriovenous fistulas due to KTW-S may predispose to chronic lymphedema and development of vascular neoplasms, or if there are molecular mechanisms related to the pathogenesis of this syndrome that may be implicated in the oncogenic process.

\section{Conclusion}

KTW-S is characterized by congenital vascular malformations and it has been associated with the presence of angiosarcomas. Since lower limbs are the most common sites involved in patients with KTW-S, development of vascular neoplasms in this location may be more frequent. However, the appearance of angiosarcomas in the breast has never been reported in the literature before in patients with KTW-S, and health-care professionals should be aware of their diagnosis and early treatment due to their aggressiveness and tendency to recur.

\section{Conflicts of interest}

The authors declare that they have no competing interests. 


\section{Acknowledgments}

We acknowledge Dr. Braulio Martínez for performing the histopathological analysis in this case.

\section{Ethical disclosures}

Protection of human and animal subjects. The authors declare that the procedures followed were in accordance with the regulations of the relevant clinical research ethics committee and with those of the Code of Ethics of the World Medical Association (Declaration of Helsinki).

Confidentiality of data. The authors declare that they have followed the protocols of their work center on the publication of patient data.

Right to privacy and informed consent. The authors have obtained the written informed consent of the patients or subjects mentioned in the article. The corresponding author is in possession of this document.

\section{References}

1. Simas A, Matos C, Lopes da Silva R, et al. Epithelioid angiosarcoma in a patient with klippel-trénaunay-weber syndrome: an unexpected response to therapy. Case Rep Oncol. 2010;3:148-53.

2. Ploegmakers MJ, Pruszczynski M, De Rooy J, Kusters B, Veth RP. Angiosarcoma with malignant peripheral nerve sheath tumour developing in a patient with klippel-trénaunay-weber syndrome. Sarcoma. 2005;9:137-40.

3. Timur AA, Driscoll DJ, Wang Q. Biomedicine and diseases: the klippel-trenaunay syndrome, vascular anomalies and vascular morphogenesis. Cell Mol Life Sci. 2005;62:1434-47.

4. Ruocco V, Schwartz RA, Ruocco E. Lymphedema - an immunologically vulnerable site for development of neoplasms. J Am Acad Dermatol. 2002;47:124-7.

5. Kudva R, Perveen S, Janardhana A. Primary epithelioid angiosarcoma of bone: a case report with immunohistochemical study. Indian J Pathol Microbiol. 2010;53:811-3.

6. McKeown D, Boland P. Stewart-Treves syndrome: a case report. Ann R Coll Surg Engl. 2013;95:e80-2.

7. Zahm SH, Fraumeni JF Jr. The epidemiology of soft tissue sarcoma. Semin Oncol. 1997;24:504-14.

8. Wang J, Fisher C, Thway K. Angiosarcoma of the breast with solitary metastasis to the ovary during pregnancy: an uncommon pattern of metastatic disease. Case Rep Oncol Med 2013;2013:209610.

9. Tian XL, Kadaba R, You SA, et al. Identification of an angiogenic factor that when mutated causes susceptibility to klippel-trenaunay syndrome. Nature. 2004;427:640-5.

10. Cha SH, Romeo MA, Neutze JA. Visceral manifestations of Klippel-Trenaunay syndrome. Radiographics. 2005;25:1694-7.

11. Mneimneh S, Tabaja A, Rajab M. Klippel-trenaunay syndrome with extensive lymphangiomas. Case Rep Pediatr. 2015;2015:581394.

12. Wang ZK, Wang FY, Zhu RM, Liu J. Klippel-trenaunay syndrome with gastrointestinal bleeding, splenic hemangiomas and left inferior vena cava. World J Gastroenterol. 2010;16:1548-52.

13. Karim $T$, Singh $U$, Nanda NS. A rare presentation of klippel-trenaunay syndrome. Indian Dermatol Online. J 2014;5:154-6. 